\title{
Dynamic Effect of Cold-Air Bypass Valve for Compressor Surge Recovery and Prevention in Fuel Cell Gas Turbine Hybrid Systems
}

\author{
Luca Mantelli ${ }^{1,}$, David Tucker ${ }^{2 *}$, and Mario Luigi Ferrari ${ }^{1}$ \\ ${ }^{1}$ Thermochemical Power Group (TPG), University of Genoa, Via Montallegro 1, 16145 Genova, Italy \\ ${ }^{2}$ National Energy Technology Laboratory, Department of Energy, Morgantown, 26507 WV, USA
}

\begin{abstract}
A large volume between compressor and turbine is present in fuel cell gas turbine hybrid systems. The substantially larger compressor plenum volume modifies the dynamic behaviour of these systems, increasing the risk of compressor surge during transients and subsequent destruction of both turbomachinery and fuel cell components. Diverting part of the compressor inlet flow directly to the turbine inlet through a cold-air bypass valve, bypassing the fuel cell stack, has been proven to be an effective method to increase the surge margin during normal operation and also to recover the machine from fully developed surge. This study investigates the dynamic effect of different cold-air bypass valve opening/closing procedures, especially steps and ramps changing the valve fractional opening. This analysis was carried out with reference to the Hybrid Performance (Hyper) facility: a hybrid system emulated using hardware and a cyber-physical fuel cell system at the National Energy Technology Laboratory (NETL), U.S. Department of Energy (DOE). Simulations performed on a Matlab ${ }^{\circledR}$-Simulink ${ }^{\circledR}$ dynamic model of the system based on Greitzer's theory showed a different behaviour varying the valve fractional opening with steps or ramps. Many experimental tests were performed on the Hyper facility to confirm the trends obtained from the simulations results. From the outcomes of this study, it has been possible to determine how to maximize the surge recovery effect of the cold-air bypass valve opening and to minimize surge related risks during the valve closure.
\end{abstract}

\section{Introduction}

Fuel cells are electrochemical reactors that generate electrical power from fuel oxidization without combustion and they are considered one of the most promising energy systems thanks to their high electric efficiency and low environmental impact [1]. An SOFC is characterized by high operative temperatures [2] and thus it can be properly embedded in a hybrid system, using its thermal output as a suitable energy source for a gas turbine, further increasing the overall efficiency [3]-[5]. Nevertheless, compared to a typical gas turbine layout, a hybrid system presents a much larger volume between compressor and turbine, which alters the compressor behaviour during transients and may increase the risks of

\footnotetext{
* Corresponding author: david.tucker@netl.doe.gov
} 
components destruction because of surge [6], [7]. To explore the dynamic operation of hybrid systems, the Hybrid Performance (Hyper) facility was designed and built at the National Energy Technology Laboratory (NETL), U.S. Department of Energy (DOE). Many studies carried out on the Hyper facility [7]-[10] showed that diverting part of the compressor outlet flow to the compressor inlet, bypassing the stack volume through the $\mathrm{CAB}$ valve, is an effective way to increase the surge margin, because of the discharge pressure reduction and mass flow increment. However, the effect of different opening and closing procedures for this valve has not been studied yet. The main goal of this work is to analyse the different responses of the compressor in an SOFC gas turbine hybrid system varying the $\mathrm{CAB}$ valve FO with steps or ramps, focusing the attention on the surge margin. This analysis is performed running both numerical simulations of a dynamic model and experimental tests on the Hyper facility.

\section{Experimental facility}

The Hyper facility is an SOFC gas turbine hybrid system emulator composed of real devices, cyber-physical components and virtual models (Fig. 1).

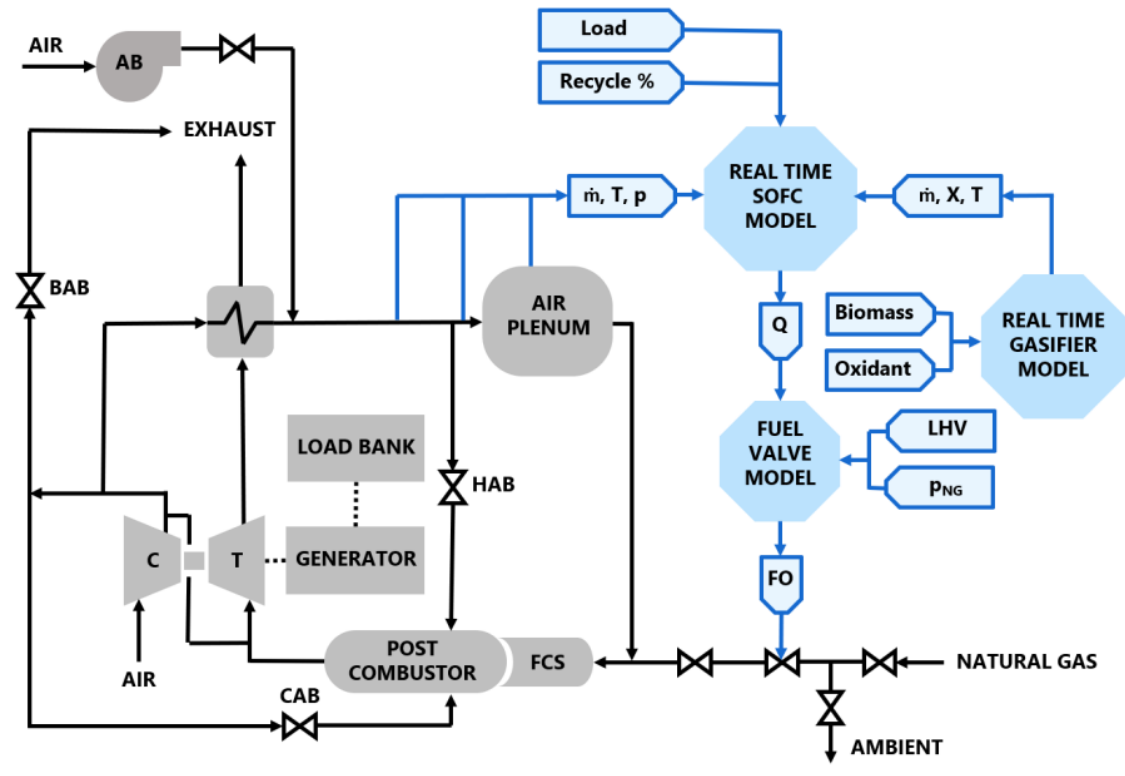

Fig. 1. Plant layout and real time models flow diagram of the Hyper system at NETL.

The turbomachine is a $120 \mathrm{~kW}$ Garrett Series 85 auxiliary power unit, where a two-stage radial compressor is directly coupled with a turbine. The gas burner (FCS) exhausts expand in the turbine, driving the compressor and pressurizing the inlet air flow. The electrical power is generated by a synchronous alternator and dissipated by a resistor load bank. The system can be run with or without an active control on the fuel mass flow to keep the gas turbine rotational speed constant (closed or open loop respectively). There is no real SOFC in this system, but its behaviour is simulated with a real-time model on the basis of the flow physical properties at the Air Plenum inlet. The natural gas flow to the FCS is controlled in order to have a turbine inlet temperature in accordance to the value computed by the SOFC model. Two pressure vessels, the Air Plenum and the Post Combustor, emulate the fuel cell and gasifier volumes. The system includes also heat exchangers to pre-heat the compressed air flow, an auxiliary air blower and many valves. In this work the attention is focused on the 
$\mathrm{CAB}$ valve, which is used to divert part of the compressor outlet flow to the Post Combustor, bypassing the heat exchanger, the Air Plenum and the FCS. The Hyper is equipped with a set of sensors used to measure physical properties in the key sections of the plant and the turbomachinery rotational speed. More information regarding the Hyper facility can be found in [11], [12].

\section{Dynamic model and simulations results}

Before running experimental tests on the Hyper, some simulations were run to check if step or ramp variations of the $\mathrm{CAB}$ valve FO could have a different effect on the compressor dynamics in a system characterized by large volumes. For this purpose, a model previously developed in Matlab $^{\circledR}$-Simulink ${ }^{\circledR}$ environment was used in collaboration between TPG and NETL. This model is based on the work presented by Greitzer in [6] to predict the compressor behaviour when its operating point changes between a stable condition and surge. The original model includes a compressor, a throttle valve, a duct and a plenum and it was properly modified to better match with the Hyper plant layout, adding a turbine, a combustor and a shaft. Since the compressor characteristic were known only for stable conditions, it was also necessary to extend its maps beyond the surge line to simulate its behaviour in the unstable regions. The compressor model is based on an actuator disk, which computes the pressure rise, and a constant area pipe, which simulates the compressor fluid dynamics. The plenum model is used to simulate the effect of the system volume, considering the potential energy related to gas pressure and neglecting the kinetic energy. The turbine model is based on steady state performance maps, while the shaft model computes the gas turbine energy balance. The valve model is composed of an actuator disk, where the mass flow is obtained on the basis of the valve area and fractional opening, and a duct. For further details regarding this model development and validation, the reader is referred to [13].

Simulations were run both in open and in closed loop, changing the mass flow through the $\mathrm{CAB}$ valve in order to move between a safe state and one closer to surge or in a surge condition. The valve openings and closings were performed with steps or ramps. Since the results in open and closed loop are similar, only those relative to the open loop simulations are reported here for the sake of brevity (Fig. 2).

To evaluate the distance from the surge condition, the surge margin $K_{p}$ is considered, defined as in (1).

$$
K_{p}=\frac{\beta_{\text {surge line }} / \dot{m}_{\text {surge line }}}{\beta / \dot{m}}
$$

Lowering the $\mathrm{CAB}$ valve $\mathrm{FO}$ from $20 \%$ to $5 \%$, the compressor operates closer to surge condition. If the valve closing is performed with a step (Fig. 2a), instabilities occur temporarily even if the compressor is not in surge when the system reaches a steady condition. When the valve is opened back to the starting point, it is possible to observe a quick increase of $K_{p}$, which exceeds the steady-state value for a short time. Performing the same mass flow variations, but with a ramp with rate of $0.6 \% / \mathrm{s}$ there are no instabilities going closer to the surge condition and the $K_{p}$ increases regularly during the valve opening (Fig. 2b).

Lowering the $\mathrm{CAB}$ valve $\mathrm{FO}$ from $20 \%$ to $1 \%$, the compressor experiences a full surge condition. With a step the oscillations start immediately, and their amplitude grows for $10 \mathrm{~s}$ before stabilizing (Fig. 2c). Opening the valve back the oscillations decrease quickly and $K_{p}$ has a substantial increase before reaching its starting value, similarly to what has been observed in the previous step simulation. 

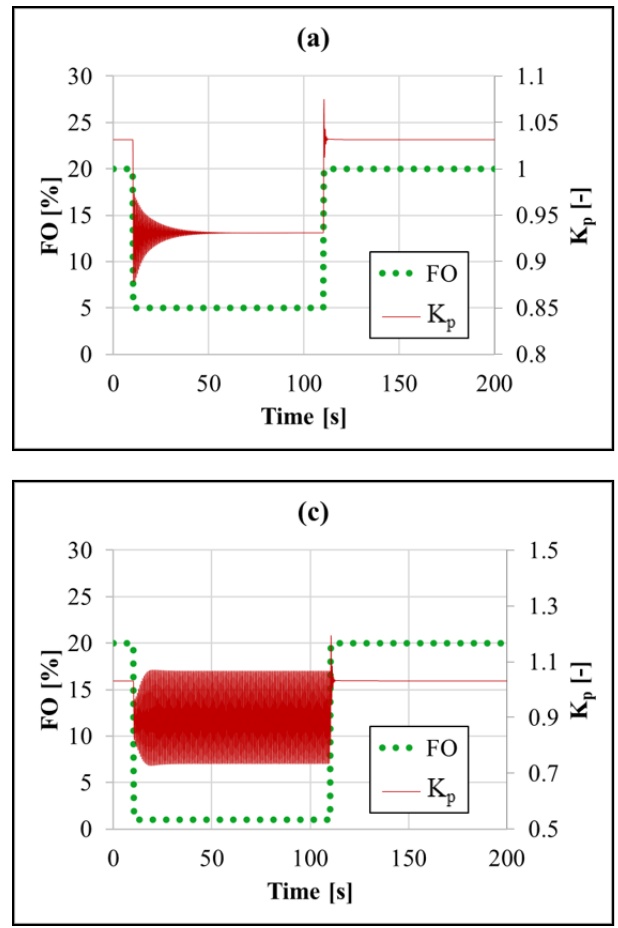

(b)

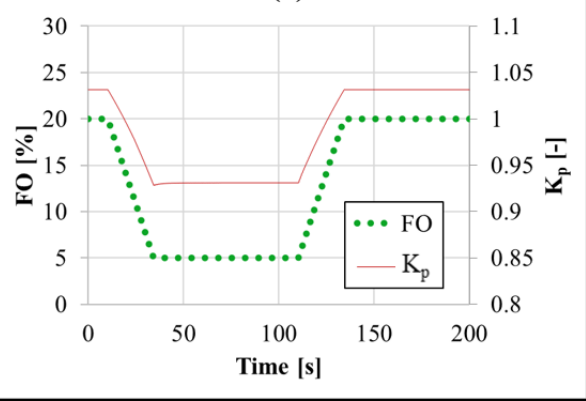

(d)

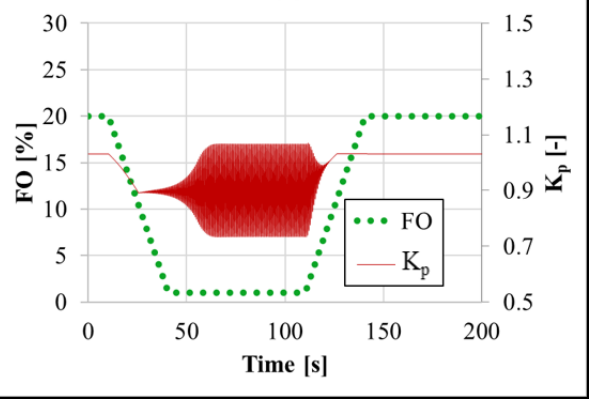

Fig. 2. Throttle valve fractional opening and compressor surge margin opening and closing the valve with steps (a) (c) and ramps (b) (d).

For the whole time required to close the bypass valve with a ramp (Fig. 2d), there are no oscillations and, when the ramp is over, it takes about $38 \mathrm{~s}$ for them to reach the full amplitude. While the valve is being opened back the oscillations amplitude decreases gradually and they disappear when $K_{p} \approx 1$. After that the surge margin increases back to the starting point regularly.

According to these results, modifying the bypass valve opening using a step or a ramp there should be a different effect on the dynamic behaviour of the system, but not on its steady-state condition.

\section{Experimental results}

To check the validity of these results on a real plant, a series of tests have been performed on the Hyper facility, operating the compressor always in a stable condition to preserve the system integrity. It is easier to compare the experimental results with the simulations showed in Fig. 2a and Fig. 2b, because in these cases the compressor steady operating conditions are always stable. However, even if the system does not experience surge during the experimental tests, it is still possible to draw some conclusions comparing the surge margin trends during the valve openings and closings with the simulations showed in Fig. 2c and Fig. 2c.

Since this work main goal is to study the effect on the compressor surge due to the large volumes that characterize fuel cell gas turbine hybrid systems, it was not necessary to run the SOFC real-time model and to emulate its thermal outcome.

Four sets of experiments have been carried on: ramps in closed loop (Fig. 3a), ramps in open loop (Fig. 3b), steps in closed loop (Fig. 3c), steps in open loop (Fig. 3d). Each set is composed of 10 openings and closings of the $\mathrm{CAB}$ valve, varying its $\mathrm{FO}$ between $70 \%$ and 
$40 \%$ with rate $0.5 \% / \mathrm{s}$. The measurements collected during each set were averaged between the 10 repetitions and filtered with a moving average, in order to remove the data noise and better understand the system response. Processing the test data, it was observed that it is not possible to evaluate effectively the distance from the surge condition with $K_{p}$, because the collected data are too noisy to understand this parameter trend (the noise obscures most of the information computing the ratio $(\beta / \dot{m})$ in $(1))$. Therefore, the distance $D_{s}$ between the surge line and the operating point on the compressor $\beta$ - $\dot{m}$ map was used. In general, the minimum distance $d$ between a point $\left(x_{0}, y_{0}\right)$ and a line of equation $a x+b y+c=0$ can be computed according to (2).

$$
d\left(a x+b y+c=0,\left(x_{0}, y_{0}\right)\right)=\frac{\left|a x_{0}+b y_{0}+c\right|}{\sqrt{a^{2}+b^{2}}}
$$

Fitting the Hyper plant compressor surge line with a linear equation and substituting the coefficients in (2), it was possible to obtain the equation (3) used to compute $D_{s}$.

$$
D_{s}=\frac{|\beta-2.0423 \cdot \dot{m}-0.1602|}{\sqrt{(-2.0423)^{2}+1^{2}}}
$$

In Fig. 3 it is plotted also $\mathrm{D}_{s, n f}$, which is the distance from surge computed on not filtered data.
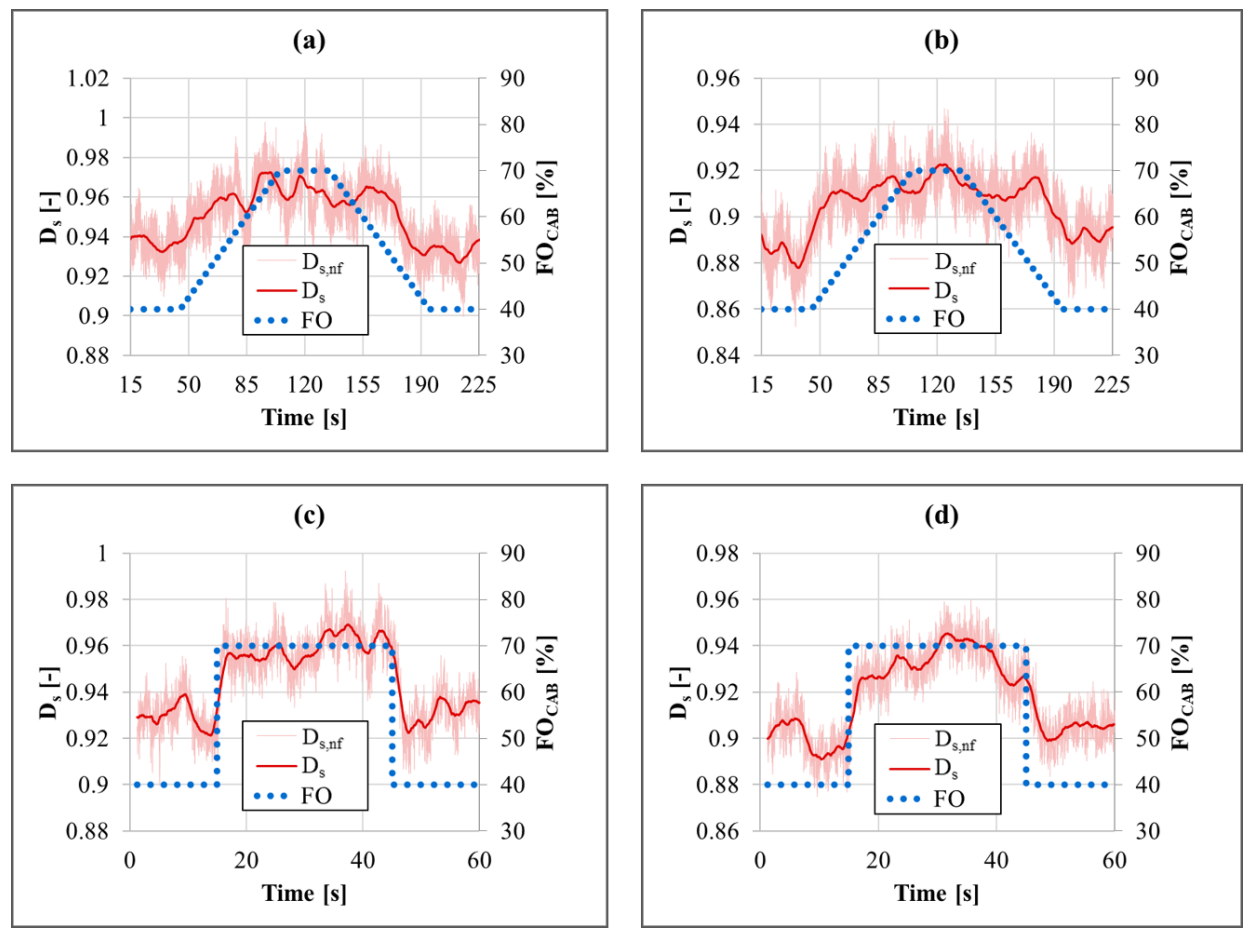

Fig. 3. CAB valve fractional opening and $D_{s}$, opening and closing the valve with ramps in closed loop (a), ramps in open loop (b), steps in closed loop (c) and steps in open loop (d).

From these results it is confirmed that, both in closed and in open loop, opening the CAB valve with a step is the quickest procedure when it is necessary to move the compressor operative point far from surge. Moreover, it has been observed that the $D_{s}$ steady state values are not significantly affected by the valve opening/closing procedure, but only by the starting and ending FO values (in all the four plots in Fig. 3 the $D_{s}$ variation is always $\sim 0.03$ ). Because 
of the data noise, it is difficult to draw conclusions regarding the temporary increase of the surge margin showed in Fig. 2a and Fig. 2c, but it is possible to observe that a $\mathrm{D}_{s, n f}$ spike is present in Fig. $3 \mathrm{c}$ during the valve opening.

\section{Conclusions}

The main goal of this paper was to study the dynamic effect of the $\mathrm{CAB}$ valve in the Hyper emulator plant, focusing the attention on the compressor surge margin. To do this both simulations and experimental tests have been run, opening and closing the valve with steps and ramps of its fractional opening. From the analysis of both simulations and experimental results, it was observed that the $\mathrm{CAB}$ valve opening/closing procedure has no significant influence on the steady compressor operative point. From these results it was also possible to state that a step opening is the quickest and most effective way of opening the $\mathrm{CAB}$ valve to drive the compressor far from surge condition. According to the simulation results, closing the valve with a ramp is an effective way of preventing temporary compressor instabilities when it is driven close to a surge condition, compared to a step. Moreover, a ramp prevents oscillations during the whole valve closure and delays the growth of their amplitude. It was not possible to validate these results on the Hyper facility because the compressor has been always kept in a stable operating point for safety issues and oscillations never occurred. In the future this aspect could be further investigated performing tests closer to surge. To understand if the sudden increase of $K_{p}$ observed during the valve opening in the simulations takes place running the real plant, more experimental tests should be run in the future reducing the measurements noise. However, the results collected performing steps in closed loop are promising in that way.

This project has received funding from the European Union's Horizon 2020 research and innovation programme under grant agreement No 641073, Bio-HyPP project (http://www.bio-hypp.eu).

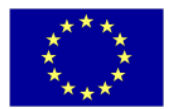

\section{Nomenclature}

\begin{tabular}{llll}
\multicolumn{2}{l}{ Abbreviations } & & \\
$\mathrm{AB}$ & Air Blower & HAB & Hot Air Bypass \\
BAB & Bleed Air Bypass & nf & Not filtered \\
CAB & Cold Air Bypass & NG & Natural gas \\
FCS & Fuel Cell Simulator & SOFC & Solide Oxide Fuel Cell
\end{tabular}

\section{Variables}

$D_{s} \quad$ Distance from surge [-]

FO Fractional Opening [\%]

$K_{p} \quad$ Surge margin [-]

LHV Lower heating value $[\mathrm{kJ} / \mathrm{kg}]$

$\dot{m} \quad$ Mass flow [kg/s]

$\begin{array}{ll}p & \text { Pressure }[\mathrm{kPa}] \\ Q & \text { Heat }[\mathrm{kW}] \\ T & \text { Temperature }[\mathrm{K}] \\ X & \text { Mass composition [\%] } \\ \beta & \text { Pressure ratio [-] }\end{array}$




\section{References}

[1] A. Buonomano, F. Calise, M. D. D’Accadia, A. Palombo, and M. Vicidomini, "Hybrid solid oxide fuel cells-gas turbine systems for combined heat and power: A review," Applied Energy, vol. 156. Elsevier Ltd, pp. 32-85, 2015.

[2] S. J. McPhail, A. Aarva, H. Devianto, R. Bove, and A. Moreno, "SOFC and MCFC: Commonalities and opportunities for integrated research," in International Journal of Hydrogen Energy, 2011, vol. 36, no. 16, pp. 10337-10345.

[3] M. A. Azizi and J. Brouwer, "Progress in solid oxide fuel cell-gas turbine hybrid power systems: System design and analysis, transient operation, controls and optimization," Appl. Energy, vol. 215, pp. 237-289, Apr. 2018.

[4] X. Zhang, S. H. Chan, G. Li, H. K. Ho, J. Li, and Z. Feng, "A review of integration strategies for solid oxide fuel cells," Journal of Power Sources, vol. 195, no. 3. pp. 685-702, 2010.

[5] A. Cuneo, V. Zaccaria, D. Tucker, and A. Sorce, "Gas turbine size optimization in a hybrid system considering SOFC degradation," Appl. Energy, vol. 230, pp. 855-864, 2018.

[6] E. M. Greitzer, "Surge and Rotating Stall in Axial Flow Compressors-Part I: Theoretical Compression System Model," J. Eng. Power, vol. 98, no. 2, p. 190, 2010.

[7] D. Tucker, L. Shadle, and N. F. Harun, "Automated compressor surge recovery with cold air bypass in gas turbine based hybrid systems," in International Symposium on Transport Phenomena and Dynamics of Rotating Machinery, 2017, pp. 1-5.

[8] P. Pezzini, S. Celestin, and D. Tucker, "Control Impacts of Cold-Air Bypass on Pressurized Fuel Cell Turbine Hybrids," J. Fuel Cell Sci. Technol., vol. 12, no. 1, p. 011006, Feb. 2014.

[9] D. Tucker, L. Lawson, and R. Gemmen, "Characterization of Air Flow Management and Control in a Fuel Cell Turbine Hybrid Power System Using Hardware Simulation," in ASME Power Conference, 2005, pp. 959-967.

[10] V. Zaccaria, D. Tucker, and A. Traverso, "Transfer function development for SOFC/GT hybrid systems control using cold air bypass," Appl. Energy, vol. 165, pp. 695-706, Mar. 2016.

[11] P. Pezzini, D. Tucker, and A. Traverso, “Avoiding Compressor Surge During Emergency Shutdown Hybrid Turbine Systems," J. Eng. Gas Turbines Power, vol. 135, no. 10, p. 102602, 2013.

[12] N. Zhou, C. Yang, D. Tucker, P. Pezzini, and A. Traverso, "Transfer function development for control of cathode airflow transients in fuel cell gas turbine hybrid systems," Int. J. Hydrogen Energy, vol. 40, no. 4, pp. 1967-1979, Jan. 2015.

[13] A. Abrassi, A. Traverso, and L. Ferrari, "Turbocharger-Based Hybrid Systems: Modeling and Validation of a Free Spool Subject to Compressor Surge," in ASME Turbo Expo 2018, 2018. 